\title{
Article \\ Effect of Cold Pressing and Aging on Reduction and Evolution of Quenched Residual Stress for Al-Zn-Mg-Cu T-Type Rib
}

\author{
Yaoqiong Liu ${ }^{1,2,3}$, Tao Zhang ${ }^{1,2, *}$, Hai Gong ${ }^{1,2}$ and Yunxin Wu ${ }^{1,2}$ \\ 1 Light Alloy Research Institute, Central South University, Changsha 410083, China; \\ yaoqiongliu_11@163.com (Y.L.); gonghai@csu.edu.cn (H.G.); wuyunxin@csu.edu.cn (Y.W.) \\ 2 State Key Laboratory of High-Performance Complex Manufacturing, Central South University, \\ Changsha 410083, China \\ 3 College of Mechanical and Electrical Engineering, Central South University, Changsha 410083, China \\ * Correspondence: larizhangtao@csu.edu.cn
}

Citation: Liu, Y.; Zhang, T.; Gong, H.; $\mathrm{Wu}, \mathrm{Y}$. Effect of Cold Pressing and Aging on Reduction and Evolution of Quenched Residual Stress for Al-Zn-Mg-Cu T-Type Rib. Appl. Sci. 2021, 11, 5439. https://doi.org/ 10.3390/app11125439

Academic Editor: Wilma Polin

Received: 18 May 2021

Accepted: 9 June 2021

Published: 11 June 2021

Publisher's Note: MDPI stays neutral with regard to jurisdictional claims in published maps and institutional affiliations.

Copyright: (c) 2021 by the authors. Licensee MDPI, Basel, Switzerland. This article is an open access article distributed under the terms and conditions of the Creative Commons Attribution (CC BY) license (https:// creativecommons.org/licenses/by/ $4.0 /)$.

\begin{abstract}
The preparation of the Al-Zn-Mg-Cu T-type rib consisted of forging, quenching, cold pressing, aging and the final machining processes, and the evolution of residual stress played a significant role in its properties and accuracy. Numerical models were established to investigate the evolution and distribution of residual stress for the T-type rib during the quenching and cold pressing processes. The results showed that the distribution of residual stress at the stiffened area is asymmetrical, which is different from the symmetrical distribution at the smooth area. The cold pressing is beneficial for the reduction of residual stress. The stepwise cold pressing resulted in the heterogeneous distribution of residual stress at the stiffened area and the overlap region. Three comparative T-type ribs were conducted, and their residual stresses were measured using X-ray diffraction and the contour method. A stress reduction of $50 \%$ can be obtained at the surfaces of the T-type rib through cold pressing followed by the aging process. The reduction of the maximum tensile stress at the stiffened area of the T-type rib was $42 \%$ and $50 \%$ for the cold pressing and aging, respectively, which increased to $54 \%$ and $60 \%$ at the smooth area. The mechanism of the stress reduction during the cold pressing and the aging processes was discussed.
\end{abstract}

Keywords: T-type rib; residual stress; quenching; cold pressing; artificial aging; stress reduction mechanism

\section{Introduction}

The key material of the main load-bearing components for the airline (such as stringer and reinforced bulkhead) is 7050 aluminum alloy (Al-Zn-Mg-Cu), due to its excellent performances of high strength and fatigue toughness, good formability, corrosion resistance and hardenability [1,2]. Furthermore, 7050 aluminum alloy is strengthened through the precipitation of strengthening phases into the Al matrix by the aging treatments [3]. The generally accepted precipitation sequence for 7000 series alloys [4] can be expressed as: supersaturated solid solution (SSS) $\rightarrow$ coherent Guinier Preston zones (G.P zones) $\rightarrow$ semicoherent $\eta^{\prime}$ phase $\rightarrow$ equilibrium phase $\eta\left(\mathrm{MgZn}_{2}\right)$. Numerous studies have indicated that $\eta^{\prime}$ phases and their precursors (G.P zones) were the main strengthening precipitates, while an incoherent $\eta$ phase cannot contribute to the strength increase. A supersaturated solid solution formed during the solution treatment contributed to the precipitation of strengthening phases during the aging process. However, the solution treatment induced large residual stress of the component, which led to severe distortion and even failure in the subsequent machining stage. The variation and control of residual stress during the preparation processes had been the key factor in the manufacturing of aerospace components with high accuracy and high performances. A thermo-mechanical treatment [5,6] was adopted to decrease the quenched residual stress by applying cold deformation between 
the solution and aging process. Meanwhile, the cold deformation also increased the dislocation density of the material, which contributed to the precipitation of strengthening phases and the strength increase in the aging stage $[7,8]$.

The preparation of airline components made from 7050 aluminum alloy consisted of forging, quenching, cold deformation and the followed aging processes. The variation of residual stress was quite complex and many previous studies on the evolution of residual stress have been reported. Chobaut [9] identified the parameters of the thermo-mechanical model for the quenching process using a limited number of tensile tests achieved after representative interrupted cooling paths in a Gleeble machine. Bouissa [10] established a 3D finite element model (FEM) to predict the induced distortion and residual stress of a large sized forged block during the water quenching process. The FEM model considered the coupling between the thermal, mechanical and metallurgical fields. Zhang [11] investigated the influence of temperature-dependent material properties on the evolution of plastic strain and residual stress in the forged 2A14 aluminum alloy components during the quenching process through the theory analysis, quenching experiments and numerical simulation. The results showed that the thermal expansion coefficients, yield strengths and elastic moduli played key roles in determining the magnitude of plastic strains and residual stresses. Cong [12] employed X-ray diffraction and a layer removal technique to determine the quench-induced residual stress in extruded ZK60 magnesium alloy. By the combination of two test methods, the residual stress on the surface and the center part of the component can be obtained. Masoudi [13] investigated the correlation between quench-induced residual stresses and the distortion of thin-walled parts during machining. The effects of polymer and uphill quenching methods in comparison with water quenching in the reduction of residual stresses were analyzed and the results indicated that the level of residual stress and distortion can be reduced significantly by adopting the polymer quenching method. Robinson [14] studied the influence of a delay between quenching and the cold compression on residual stresses in the heat treatable aluminum alloy 7050 . It was found that reducing the post-quench delay resulted in lower magnitude residual stresses as the aluminum alloy underwent natural aging during the delay, which changed the work hardening behavior of the alloy during subsequent cold compression. Zhang [15] investigated the influence of the cooling rate on the residual stress and tensile properties of 2A14 aluminum alloy by numerical simulation and quenching experiments. Lower cooling rates reduced the tensile strength and yield strength due to a decreased amount of fine precipitates, and reduced the residual stress with the reduction of plastic strain and the degree of inhomogeneous plastic deformation. Guo [16] established a dislocation density-based model for accurate prediction of residual stress for as-quenched $\mathrm{Al}-\mathrm{Cu}-\mathrm{Mg}$ alloy, which considered the influences of precipitation, solid solution and forest dislocation. The results showed that volume fraction of precipitates decreased with the increasing temperature and cooling rate, in contrast to the increasing trend for the radius of precipitates. The quench-induced precipitates had an influence only on the magnitudes of flow stress at low temperatures.

Cold compression [17] was adopted to relieve the quenched residual stress by many researchers, which played a significant role in the reduction of residual stress. Zheng [18] used the cold compression stress relief process to reduce the quench-induced stresses in high-strength aerospace aluminum alloy forgings. However, this method did not completely relieve the stress, and the overall reduction of peak stress magnitudes was approximately $43-79 \%$. Cui [19] investigated the effect of cold compression deformation on the distribution of quenching residual stress of 7A85 aluminum alloy thick block forging. The experimental results indicated that the optimal compression deformation value was $1-2 \%$, which reduced $70 \%$ of the residual stress for the specimens. Liu [20] determined the residual stresses through the thickness of quenched and quenched followed by cold compressed 7050 aluminum alloy using the contour method and neutron diffraction. The longitudinal residual stresses obtained by the two techniques achieved good agreement in both trend and magnitude in both the quenched and cold compressed components. Except 
for the cold compression, cold stretching was also effective in reducing the residual stress of the components with simple geometry. Ko [21] used two different methods of cold working (compression and stretching) to reduce the residual stress and the results showed that both compression and stretching processes reduced the residual stresses more than $90 \%$. However, the effect of deformation in compression and stretching on the residual stress variation was different [22]. Due to the limitations in the capacity of the cold compression machine, integral cold compression could not be conducted for the components with large size; therefore, multiple cold forging operations were adopted for the components with the larger size. Pan [23] studied the effect of the compression ratio, friction coefficient, length of overlap and length of the T-section component on the residual stress distribution during the multiple cold forging operations. A percentage reduction in the peak residual stress of over $90 \%$ was found and the optimal parameters for residual stress relief by cold compression had been obtained.

Large tensile residual stresses generated during cold working processes could negatively affect the integrity and geometric accuracy of the workpiece, and the heat treatment was adopted for the reduction of residual stress [24]. Bai [25] proposed a novel residual stress relaxation model considering the dislocation evolution mechanism and the plasticity theory to predict the change of residual stress during the annealing process. The aging heat treatment partially relieved the residual stresses generated at previous stages of forging and water quenching; however, the stress field would not be completely relaxed [26]. Zhang [27] determined the through-thickness residual stress distribution of urbine discs during the isothermal forging, solution treatment and aging treatment using neutron diffraction and 2D-detector X-ray diffraction. The results demonstrated that residual stress exhibited typical thermal stress distribution while plastic deformation-induced surface stress was relieved after the solution and aging treatment. Dong [28] investigated the effects of aging temperatures and aging times on the amount of residual stress relief for $\mathrm{Al}-\mathrm{Cu}$ forged blocks after aging treatments by a numerical simulation method and experimental measurements. The peak-aged (T6) and over-aged (T7) condition produced only about a 22.5 to $34.7 \%$ reduction in residual stresses. Aba-Perea [29] used neutron diffraction to in situ follow the evolution of residual stress of Inconel 718 during the aging process. Almost $90 \%$ of stress relaxation was found to occur primarily during heating to the aging temperature as a result of a combination of plasticity and early-stage creep relaxation. A novel multi-stage interrupted artificial aging treatment [30] was designed for reducing residual stresses in quenched $\mathrm{Al}-\mathrm{Zn}-\mathrm{Mg}-\mathrm{Cu}$ alloy thick plates. The results showed that residual stress magnitudes were reduced significantly and even eliminated completely by this novel treatment while the conventional artificial aging only contributed to a reduction of $10-35 \%$, because an inverse stress was ingeniously employed during rapid heating to release the internal residual stress. Wang [31] studied the residual stress relaxation and the texture evolution of cold-rolled AZ31 Mg alloys using the vibratory stress relief technique. It can be seen that the uniform surface residual stress distribution and relaxation of the compressive residual stress in the stress concentration zone were observed rather than all of the residual stresses being eliminated. In addition, with an increase in the vibrational aging time, the compressive residual stress, texture density and (0002) preferred orientation increased first and then decreased.

However, much previously published research focused on the variation of residual stress during a single stage, such as quenching, cold deformation or aging. Cold deformation and the aging processes both played a vital role in the reduction of residual stress; however, the contribution of these two processes on the stress relief has not been extensively investigated. In addition, the effects of cold deformation and the subsequent aging on the distribution of residual stress need to be further analyzed, especially for the components with unique geometry. In this study, a T-type rib was adopted, and numerical models were established to investigate the evolution and distribution of residual stress during the quenching and cold pressing processes. Then, three comparative T-type ribs were conducted, which were quenched, quenched-cold pressed and quenched-cold pressed- 
aged, and the distribution of residual stress was measured using X-ray diffraction and the contour method.. Finally, the mechanism of the stress reduction during the cold pressing and the aging processes was discussed.

\section{Materials and Methods}

The T-type rib, which was the critical connective component between the fuselage and wing of the airline, was adopted in this study. The preparation of the T-type rib was quite complex, which consisted of forging, quenching, cold pressing, aging and the final machining processes, as shown in Figure 1. Excellent mechanical properties and high accuracy of the T-type rib were essential for its safety as it was the main load-bearing component of the airline. A solution and aging contributed to the increase of mechanical properties; however, the residual stress was inevitably induced during the solution and quenching process. The large residual stress inside the component may cause severe distortion and even failure during the final machining stage; therefore, cold pressing was adopted for the stress relief. In general, the evolution of residual stress and its distribution were quite complex, which will affect the final mechanical properties and the accuracy of the final product. It is essential to have a better understanding of the variation of residual stress during these processes and provide guidance for the control of residual stress.

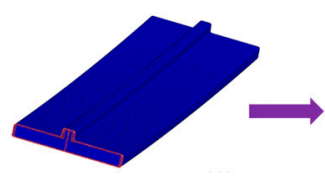

Forging

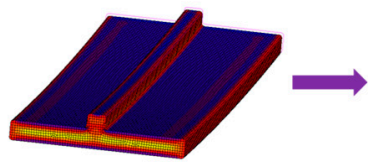

Quenching

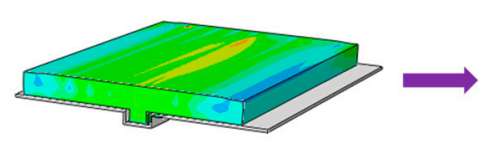

Cold pressing

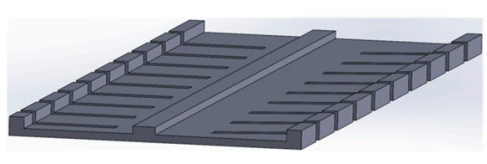

Machining

Figure 1. The preparation process of the T-type rib.

\subsection{Materials}

The material of the quenched T-type rib was forged 7050 aluminum alloy. The thermal parameters and the flow stress with the relationship to the temperatures are depicted in Table 1. The density and linear expansion coefficient were set as $2830 \mathrm{~kg} / \mathrm{mm}^{3}$ and $3 \times 10^{-5}{ }^{\circ} \mathrm{C}^{-1}$, respectively. The heat transfer coefficient between the component and the water was $10,000 \mathrm{~W} / \mathrm{m}^{2} \cdot \mathrm{K}$. Figure 2 shows the dimensions of the T-type rib and it mainly consists of the smooth area without the stiffener at both sides and the stiffened area in the middle part.

\subsection{Procedures of Treatments}

The quenching procedure was that the material was heated to $475{ }^{\circ} \mathrm{C}$ and held for $7 \mathrm{~h}$ followed by rapid water cooling.
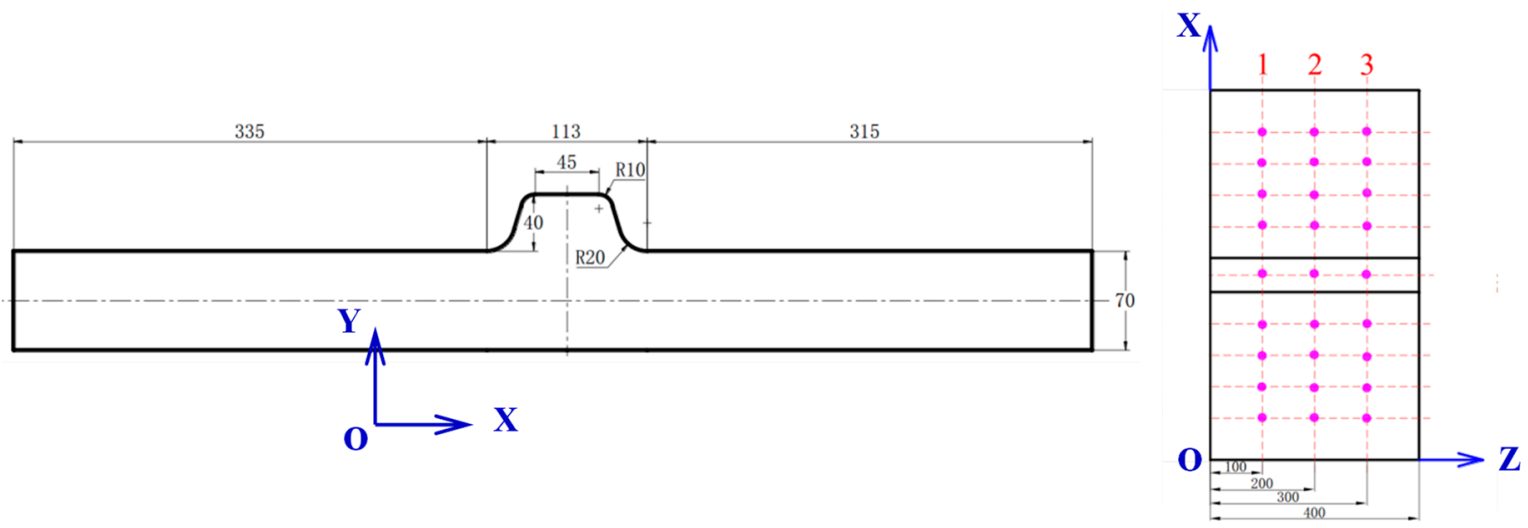

Figure 2. Dimensions of the T-type rib. 
Table 1. Parameters of 7050 aluminum alloy.

\begin{tabular}{ccccc}
\hline Temperature $\mathbf{T},{ }^{\circ} \mathbf{C}$ & $\begin{array}{c}\text { Thermal Conductivity } \\
\lambda, \mathbf{W} / \mathbf{m} \cdot{ }^{\circ} \mathbf{C}\end{array}$ & $\begin{array}{c}\text { Elastic Modulus } \boldsymbol{r}_{\boldsymbol{\prime}} \\
\mathbf{M P a}\end{array}$ & Flow Stress $\sigma, \mathbf{M P a}$ & $\begin{array}{c}\text { Specific Heat Capacity } \\
\boldsymbol{c}, \mathbf{J} / \mathbf{k g} \cdot{ }^{\circ} \mathbf{C}\end{array}$ \\
\hline 20 & 114.8 & 71,000 & 455.9 & 835 \\
100 & 128.4 & 65,193 & 389.1 & 897 \\
150 & 135.7 & 60,594 & 346.6 & 916 \\
200 & 142.2 & 56,262 & 275.7 & 974 \\
300 & 152.7 & 37,980 & 47.1 & 1013 \\
400 & 160.8 & 31,200 & 35.5 & 1128 \\
500 & 166.7 & 25,000 & 16.3 & 1205 \\
\hline
\end{tabular}

In the practical production of the T-type rib, cold pressing was adopted to decrease the residual stress after the quenching process. Due to the capacity limitation of the forging machine, the cold pressing was applied to the T-type rib step by step, as shown in Figure 3. The T-type rib was fixed in the lower mold and the plate pinch was inserted between the upper mold and the T-type rib. The first pass of the cold pressing was applied on the center part of the T-type rib and the following cold pressing was achieved on both sides symmetrically. The width of the plate pinch was $120 \mathrm{~mm}$ and the length of the overlap region was $25 \mathrm{~mm}$ for the adjacent pass. The material of the plate pinch and the molds was die steel. The pass reduction was $3 \%$ and the friction coefficient was 0.1 between the plate pinch and the T-type rib.

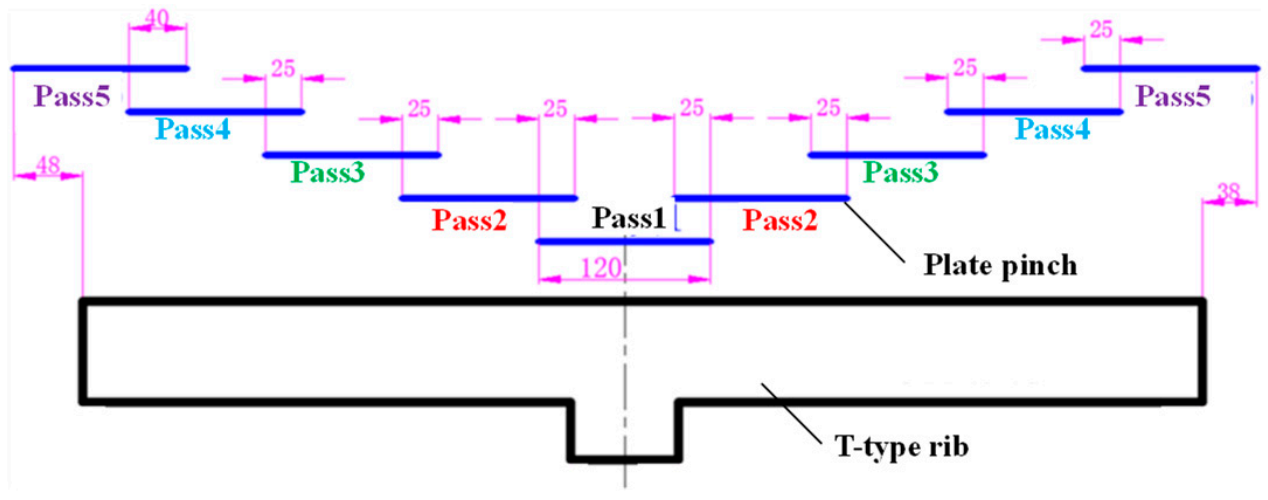

Figure 3. Schematic diagram of stepwise cold pressing process.

The artificial aging process was completed within $48 \mathrm{~h}$ after the cold pressing process to decrease the effect of natural aging. The artificial aging procedure was that the material was heated to $120^{\circ} \mathrm{C}$ and held for $8 \mathrm{~h}$ followed by air cooling.

\subsection{Methods}

\subsubsection{Numerical Models}

Numerical models of the quenched and cold pressed T-type rib were established to analyze the evolution and distribution of residual stress. It should be noted that the effects of phase transformation and the second phase on the residual stress were ignored in this model. To compare the effect of integral and stepwise cold pressing on the residual stress distribution of the T-type rib, one-pass integral cold pressing and five-pass stepwise cold pressing were conducted. The five-pass stepwise cold pressing was the same as that in Figure 3. The eight-node linear hexahedral elements (HEX C3DR8T) with the size of $10 \mathrm{~mm}$ (length) $\times 10 \mathrm{~mm}$ (width) $\times 2 \mathrm{~mm}$ (height) were adopted for the quenched and cold pressed models.

\subsubsection{Experiments}

The material and its size of the T-type rib were the same as that in the numerical models. Three comparative T-type ribs were comparatively studied: quenched, quenched and cold 
pressed, as well as quenched, cold pressed followed by artificial aged. The variation of residual stress under different processes was analyzed. The quenching procedure was the same as that in the numerical models. Five passes of the cold pressing process were applied to component $B$ and the reduction rate of each pass was 3\%. The length of the upper mold was $120 \mathrm{~mm}$, and the overlap length of the adjacent pass was $25 \mathrm{~mm}$, as shown in Figure 3 . The X-ray diffractometer (XRD, STRESSTECH OY, Jyväskylä, Finland) was adopted to measure the surface residual stress of the T-type rib. Three paths on the smooth and the stiffened surfaces were selected, and the average value of the residual stress was calculated, as shown in Figure 2. The parameters for the X-ray diffraction are shown in Table 2.

Table 2. Parameters of X-ray diffraction.

\begin{tabular}{cc}
\hline Parameters & Values \\
\hline Tube type & $\mathrm{Cr}$ \\
Current & $6.7 \mathrm{~mA}$ \\
Voltage & $30 \mathrm{kV}$ \\
Exposure times & 10 \\
Duration time of each exposure & $2 \mathrm{~s}$ \\
Collimator diameter & $3 \mathrm{~mm}$ \\
Diffraction plane & $(311)$ \\
Diffraction angle & $139.3^{\circ}$ \\
\hline
\end{tabular}

The contour method was adopted to obtain the distribution of the normal residual stress on the whole cross-section of the T-type rib. Figure 4 shows the principle of the contour method, which determined the residual stress via processes that consisted of cutting the component into two pieces and measuring the surface strain resulting from residual stress redistribution. Next, the measured data of the surface strain were used to calculate the residual stress through the finite element model. The initial normal residual stress on the surface perpendicular to the $\mathrm{x}$ axis was unknown and it could be calculated by Equation (1) based on Bueckner's superposition principle. Next, the component was cut into two pieces through the cross-section perpendicular to the $\mathrm{x}$ axis with a wirecut electrical discharge machine. Deionized water cooling was applied to minimize the thermal effect on the stress. The contour of each cutting surface was measured with a three-coordinate measuring machine and the surface strain was calculated after averaging and smoothing of the two surface contours. The calculated surface strain was imported into the FEM and the external stress $\sigma_{\mathrm{x}}{ }^{\mathrm{C}}$ was applied to the cutting surface, which recovered the deformed surface after the cutting process into the surface in Figure 4a without cutting. The normal residual stress $\sigma_{\mathrm{x}}{ }^{\mathrm{B}}$ and shear stress in this cutting surface were almost zero as the residual elastic strain was released during the cutting process. Therefore, the initial unknown residual stress $\sigma_{\mathrm{x}}{ }^{\mathrm{A}}$ was equal to the applied external stress $\sigma_{\mathrm{x}}{ }^{\mathrm{C}}$, as shown in Equation (2).

$$
\begin{gathered}
\sigma_{\mathrm{x}}^{\mathrm{A}}=\sigma_{\mathrm{x}}{ }^{\mathrm{B}}+\sigma_{\mathrm{x}}{ }^{\mathrm{C}} \\
\sigma_{\mathrm{x}}{ }^{\mathrm{A}} \approx \sigma_{\mathrm{x}}{ }^{\mathrm{C}}
\end{gathered}
$$

where $\sigma_{\mathrm{x}}{ }^{\mathrm{A}}$ is the unknown residual stress, $\sigma_{\mathrm{x}}{ }^{\mathrm{B}}$ is the residual stress after cutting and $\sigma_{\mathrm{x}}{ }^{\mathrm{C}}$ is the applied external stress that recovers the deformed surface after the cutting process into the surface without cutting.

In this study, a slow-feeding NC wire-cut machine (DK7625P) was used to cut the component into two pieces. The wire travelling speed was set as $1 \mathrm{~mm} / \mathrm{min}$ to decrease the surface roughness of the cutting surface, thus decreasing the accuracy of the residual stress calculation using the contour method. The material of the cutting wire was copper with a diameter of $0.2 \mathrm{~mm}$. After the cutting process, the three-coordinate measuring machine (MQ8106) was adopted to measure the contours of the cutting surface with an interval of $3 \mathrm{~mm} \times 3 \mathrm{~mm}$. 
(a)

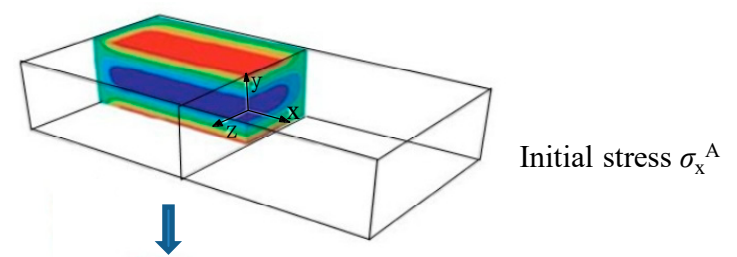

(b)

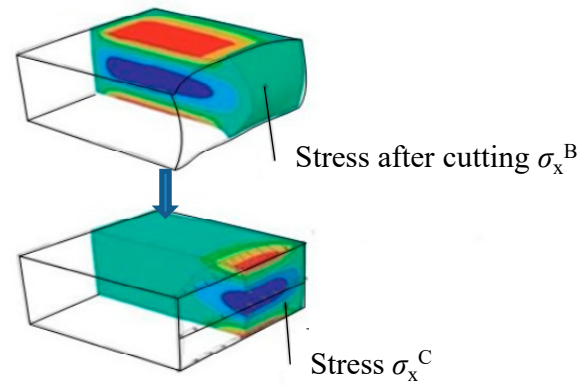

Figure 4. Principle of contour method: (a) Initial stress before cutting; (b) Stress after cutting; (c) Calculation of the initial stress.

\section{Results and Discussion}

\subsection{Numerical Simulations}

\subsubsection{Quenching Process}

The quenched T-type rib shows compressive residual stress at its outer layers and tensile residual stress at the internal layers both for the longitudinal and transverse residual stress, as shown in Figure 5. The thermal stress resulting from the temperature gradient in different positions of the component in the heating and cooling stages contributes to the formation of residual stress during the quenching process. The variation of residual stress can be explained as follows: severe shrinkage appears at the outer surface with the high temperature of the component, while there is little strain at the internal layer at the initial stage of the quenching. Inconsistent strain between the outer and internal layers impedes the shrinkage at the outer surface, resulting in tensile residual stress at the outer layers and compressive residual stress at the internal layers. The temperature at the internal layers starts to decrease due to the stable cooling velocity and the shrinkage at the internal layers increases compared to that at the outer layers. The tensile to compressive stress distribution from the outer to internal layers changes gradually. During the final stage of quenching, the temperature at the outer layer decreases to room temperature while there is still shrinkage at the internal layer during the cooling stage. According to the volume invariance, the strain at the outer layers hinders the continuous contraction of the internal layers, thus causing compressive residual stress at the outer layers and tensile residual stress at the internal layers.

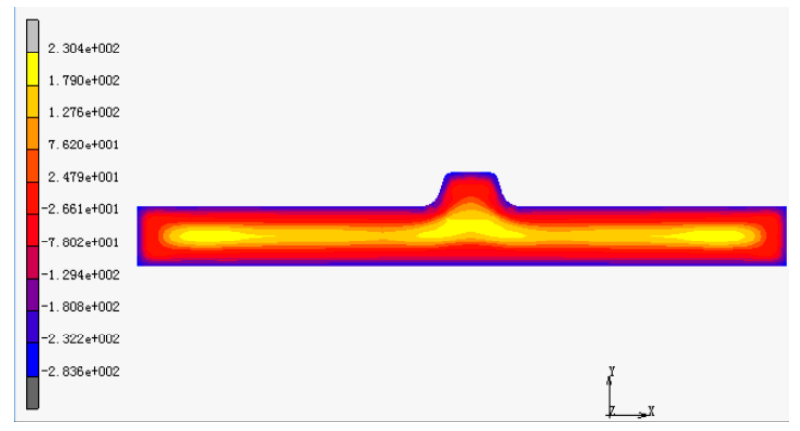

(a) longitudinal residual stress $\sigma$

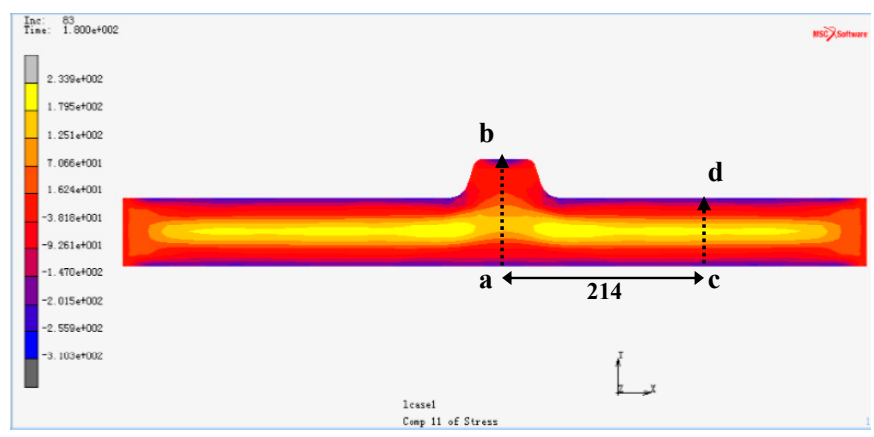

(b) transverse residual stress $\sigma_{\mathrm{xz}}$

Figure 5. Residual stress distribution of quenched T-type rib: (a) Longitudinal residual stress; (b) transverse residual stress. 
The residual stress shows a lamination distributional type at the thickness direction because of the directional heat transfer during the quenching process. The area with the stiffener shows an asymmetrical distribution of residual stress at the thickness direction of the T-type rib while that of the smooth area without the stiffener is symmetrical. Two paths (depicted in Figure 5) are plotted to describe the distribution of residual stress in the area with and without the stiffener, as shown in Figure 6. The smooth area shows approximately equal longitudinal and transverse residual stress and this is similar to the distribution of residual stress for a quenched plate. The residual stress changes from $-210 \mathrm{MPa}$ at the surface to $190 \mathrm{MPa}$ at the center point of the smooth area. Nevertheless, there is a distinct difference between the longitudinal and transverse residual stress at the center point of the area with the stiffener. The longitudinal stress varies from $-230 \mathrm{MPa}$ to $200 \mathrm{MPa}$ while the transverse stress changes from $-230 \mathrm{MPa}$ to $145 \mathrm{MPa}$, and the maximum tensile stress locates at $40 \sim 50 \mathrm{~mm}$ from the bottom surface. The stiffened area shows larger longitudinal stress compared to that of the smooth area. The existence of the stiffener increases the temperature gradient and strain inhomogeneity, thus inducing larger longitudinal residual stress. The stiffened area can be equivalent to the quenching process with larger thickness compared to the smooth area. Due to the internal balance of residual stress, larger longitudinal residual stress will give rise to smaller transverse residual stress at the stiffened area.
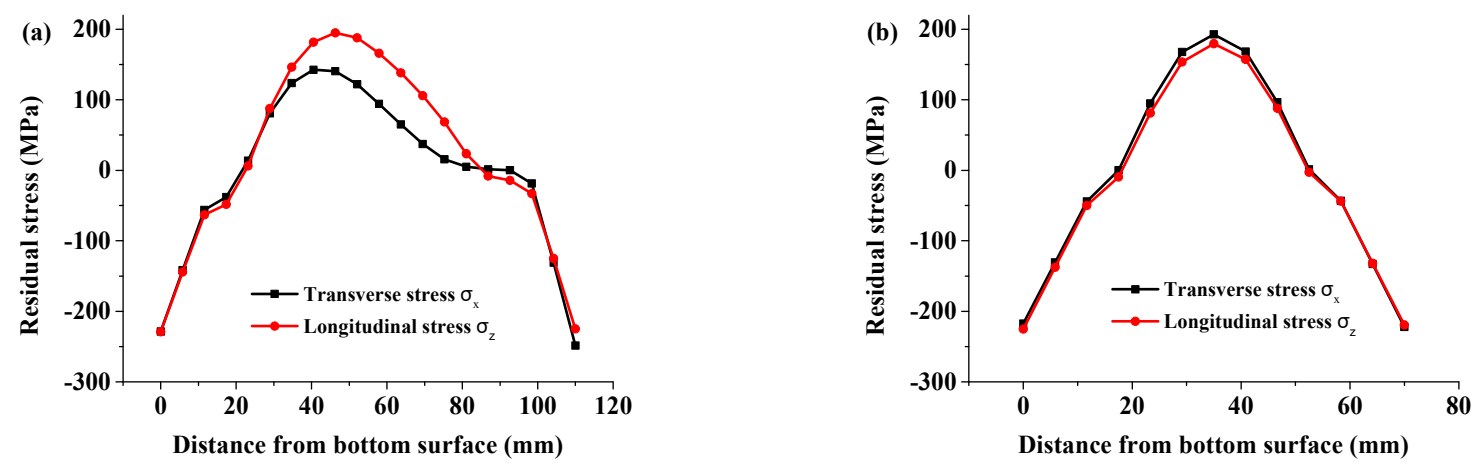

Figure 6. Residual stress distribution of quenched T-type rib: (a) path ab; (b) path cd (depicted in Figure 3).

\subsubsection{Cold Pressing Process}

Figure 7 shows the strain distribution after the first pass of the cold pressing process. A large strain zone is located at the edges of the upper mold and the area between the stiffener and the smooth plate. The contact surfaces of the T-type rib between the upper and lower molds show quite small strain due to the friction. Therefore, the asymmetric geometry and boundary conditions during the cold pressing process both contribute to the heterogeneous strain distribution. The large strain at the area between the stiffener and the smooth plate indicates the distinct residual stress relief effect.

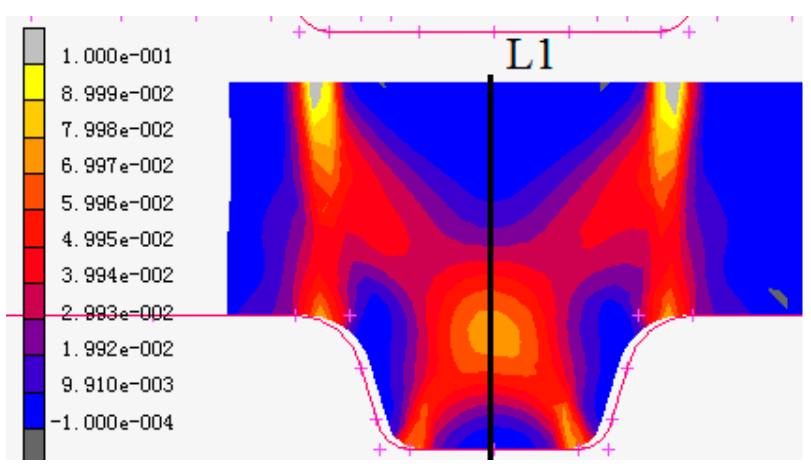

Figure 7. Strain distribution of the first pass of cold pressing. 
Figure 8 shows the residual stress distribution of one-pass integral cold pressing and five-pass stepwise cold pressing. The residual stress distribution is symmetrical and uniform at the smooth area while it is inhomogeneous at the area with the stiffener. This can be explained by the strain distribution shown in Figure 7. The stepwise cold pressing process induces inhomogeneous residual stress distribution at both the stiffened area and the smooth area of the T-type rib. It can be seen that the stress fluctuation is quite obvious at the overlap region between the adjacent pass. Therefore, less cold pressing pass is beneficial to the residual stress reduction and its distribution uniformity within the capacity of the cold forging machine.

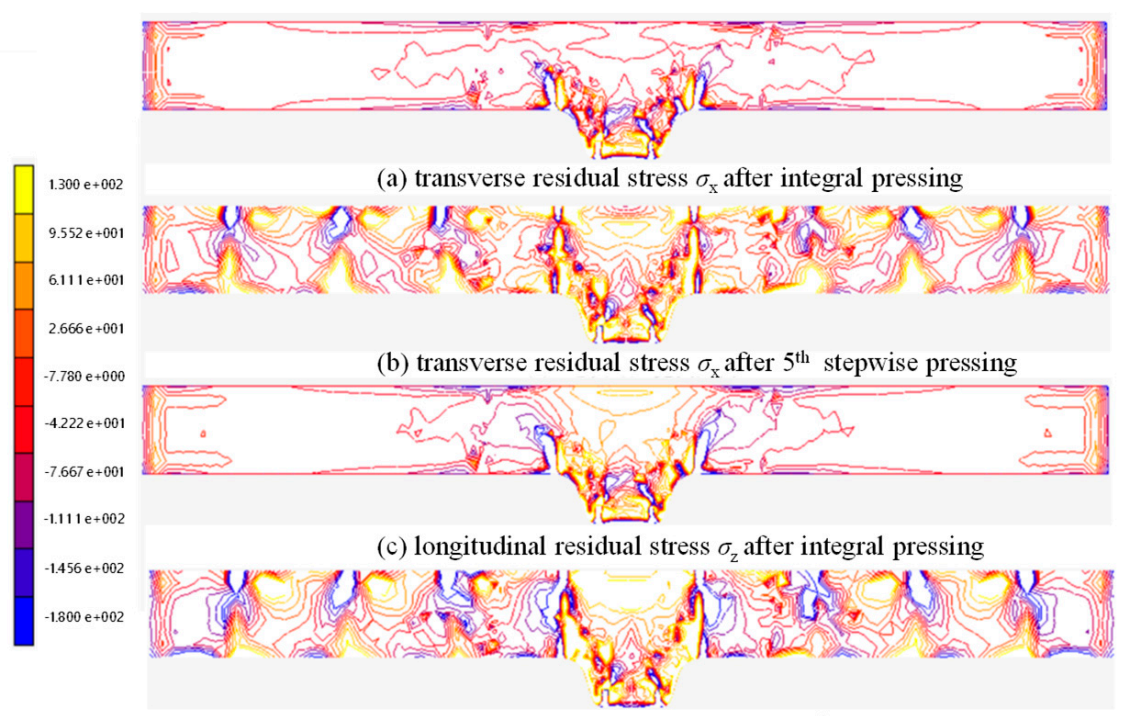

(d) longitudinal residual stress $\sigma_{z}$ after $5^{\text {th }}$ stepwise pressing

Figure 8. Residual stress distribution of the integral and five-pass stepwise cold pressing process: $(\mathbf{a}, \mathbf{c})$ is transverse and longitudinal residual stress after integral pressing, respectively; $(\mathbf{b}, \mathbf{d})$ is transverse and longitudinal residual stress after 5th stepwise pressing, respectively.

To analyze the effect of stepwise cold pressing on the residual stress reduction, two paths corresponding to Figure 5 are selected, as shown in Figure 9. Similar to the quenched stress distribution, the cold pressed stress shows symmetrical distribution at the smooth area and asymmetrical distribution at the stiffened area. Compared to the quenched stress, distinct stress reduction is achieved in the cold pressing process. The longitudinal stress decreases from $-230 \mathrm{MPa}$ and $200 \mathrm{MPa}$ to $-161 \mathrm{MPa}$ and $133 \mathrm{MPa}$; while the transverse stress decreases from $-230 \mathrm{MPa}$ and $145 \mathrm{MPa}$ to $-162 \mathrm{MPa}$ and $90 \mathrm{MPa}$ at the stiffened area. Different from the variation of residual stress at the stiffened area, there is almost no difference between the longitudinal and the transverse stress at the smooth area. The residual stress decreases from $-210 \mathrm{MPa}$ and $190 \mathrm{MPa}$ to $-145 \mathrm{MPa}$ and $81 \mathrm{MPa}$ at the smooth area.
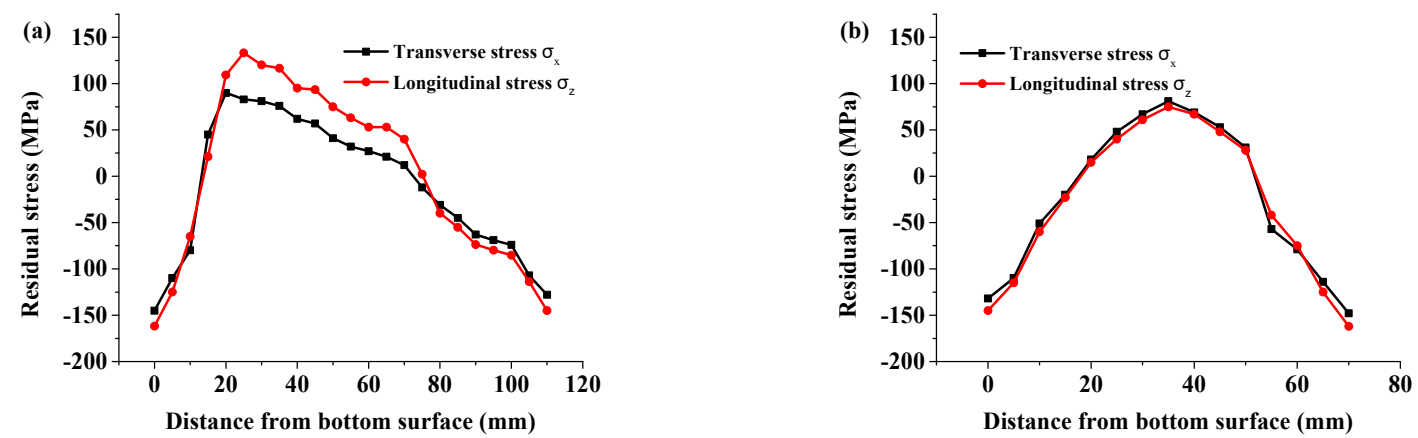

Figure 9. Residual stress distribution of cold pressed T-type rib: (a) path ab; (b) path cd (depicted in Figure 3). 


\subsection{Experimental Results}

\subsubsection{Surface Residual Stress}

Table 3 shows the average value of the residual stress on the surface of the T-type rib after different processes. The cold pressing process plays a significant role in the reduction of the residual stress. The compressive residual stress on the stiffened surface decreases from $-200 \mathrm{MPa}$ in the quenching process to around -160 MPa in the stepwise cold pressing, thus resulting in a stress reduction of $20 \%$. The residual stress on the stiffened surface further decreases to around $-100 \mathrm{MPa}$ with artificial aging, as a result, a stress reduction of $50 \%$ is achieved by the combination of cold pressing and artificial aging. It can be observed that the stress reduction on the smooth surface in the cold pressing is larger than that on the stiffened surface, indicating that the cold pressing is more effective in stress reduction of the smooth surface of the T-type rib. A total stress reduction of $50 \%$ is also obtained on the smooth surface after cold pressing followed by artificial aging.

Table 3. Average surface residual stress after different processes.

\begin{tabular}{ccccc}
\hline \multirow{2}{*}{ Process } & \multicolumn{2}{c}{ Longitudinal Residual Stress } & \multicolumn{2}{c}{ Transverse Residual Stress } \\
& Stiffened Surface & Smooth Surface & Stiffened Surface & Smooth Surface \\
\hline Quenching & $-195.5 \pm 27.5$ & $-203 \pm 29.7$ & $-200.3 \pm 29.8$ & $-202.5 \pm 30.4$ \\
Quenching + cold pressing & $-164.4 \pm 40.8$ & $-132.2 \pm 26.7$ & $-157.7 \pm 39.8$ & $-134.5 \pm 32.7$ \\
Quenching + cold pressing + artificial aging & $-100.5 \pm 33.8$ & $-107.4 \pm 39.8$ & $-95.3 \pm 36.9$ & $-114.3 \pm 41.3$ \\
\hline
\end{tabular}

\subsubsection{Contour Method Results}

Figure 10 shows the contours of the cutting surface of the T-type rib after different processes. The maximum value is $0.65 \mathrm{~mm}$ for the quenched surface, which decreases to $0.25 \mathrm{~mm}$ and $0.3 \mathrm{~mm}$ for the cold pressing and artificial aging surfaces, respectively. The value of the contours reveals the value of the residual stress, indicating that the cold pressing and the artificial aging both play a significant role in the reduction of the residual stress.

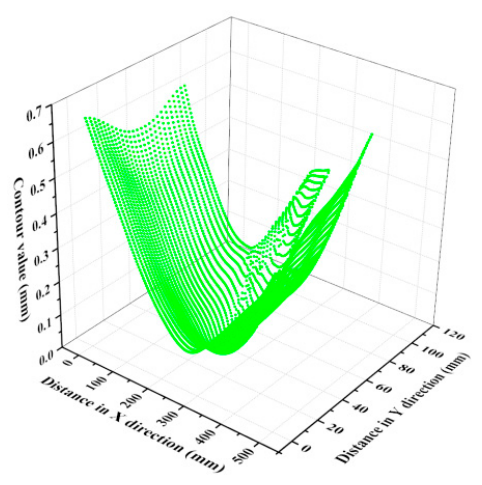

(a) Quenching

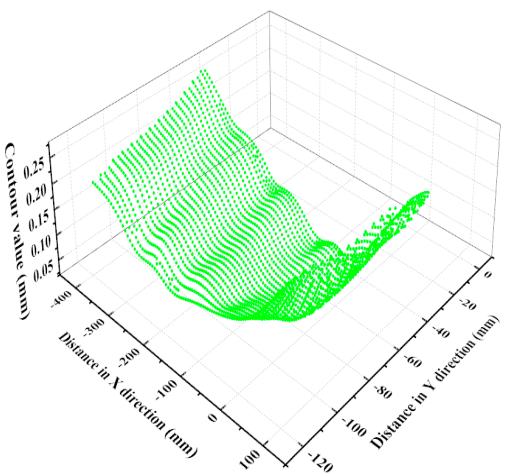

(b) Cold pressing

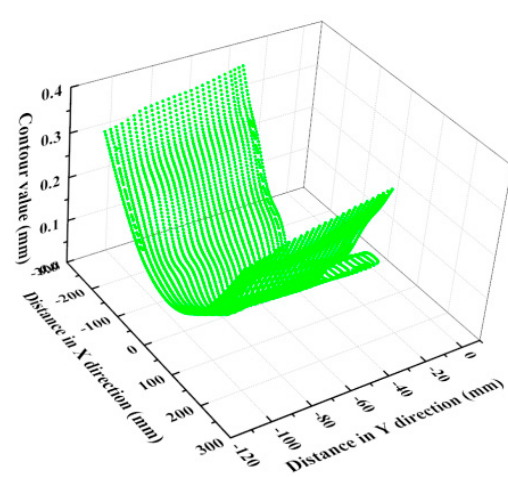

(c) Artificial aging

Figure 10. Contours of the cutting surface of the T-type rib after different processes: (a) quenching; (b) stepwise cold pressing; (c) artificial aging.

Based on the principle of the contour method described in Section 3, the longitudinal residual stress on the cutting surface can be obtained, as shown in Figure 11. It can be observed that there is a significant difference of the residual stress on the surface between the results using $X$-ray diffraction and the contour method. This can be explained as follows: the contour on the edges of the cutting surface is measured through the three-coordinate measuring machine. This may result in an inevitable error during the measurement of the contour on the edges of the surface due to the certain size of the head for the measuring machine. Therefore, significant errors of the residual stress on the surfaces of the T-type rib 
are generated. It can be seen from Figure 11 that the maximum tensile residual stress in the longitudinal direction at the stiffened area is $220 \mathrm{MPa}$ in the quenched stage, which decreases to $128 \mathrm{MPa}$ in the cold pressed stage and $110 \mathrm{MPa}$ in the artificial aged stage. As a result, a stress reduction of $42 \%$ and $50 \%$ can be achieved by the cold pressing and artificial aging process, respectively. The stress reduction at the smooth area is more significant than that at the stiffened area. The maximum tensile residual stress decreases from $175 \mathrm{MPa}$ in the quenched state to $80 \mathrm{MPa}$ in the cold pressed stage and $70 \mathrm{MPa}$ in the artificial aged stage. The stress reduction is $54 \%$ and $60 \%$ for the cold pressing and artificial aging, respectively.

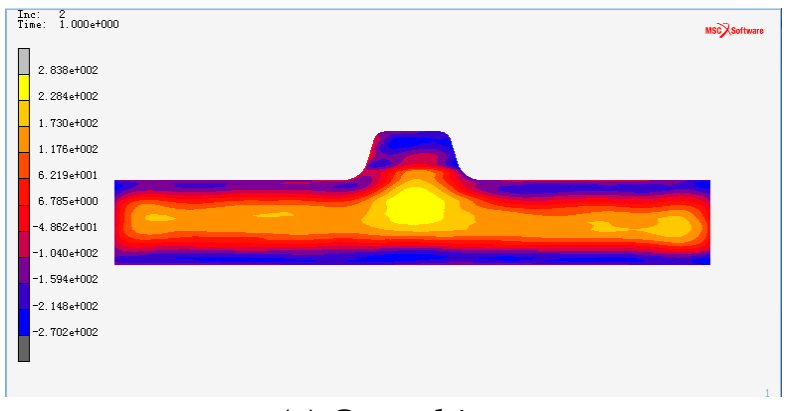

(a) Quenching

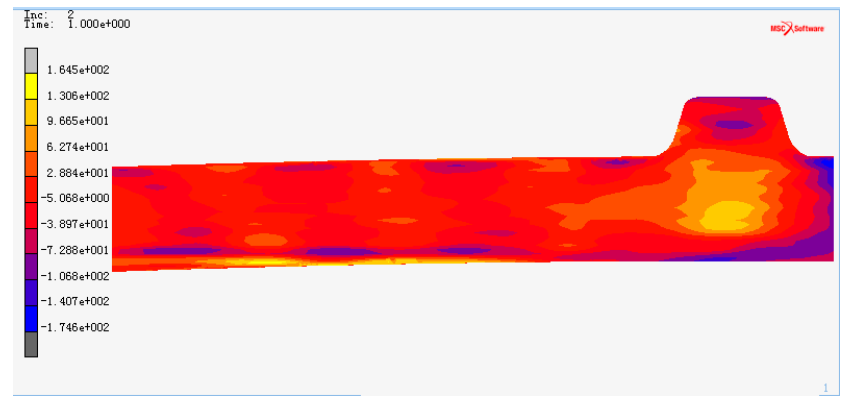

(b) Cold pressing

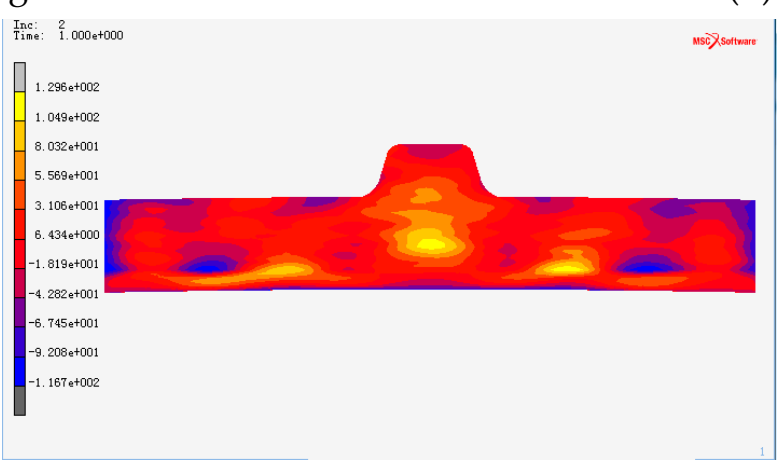

(c) Artificial aging

Figure 11. Longitudinal residual stress distribution of the cutting surface after different processes: (a) quenching; (b) stepwise cold pressing; (c) artificial aging.

As discussed above, the contour methods bring large errors of the residual stress on the edges of the surface for the T-type rib. Therefore, residual stress on the surfaces through X-ray diffraction and the stress results on other regions of the T-type rib through the contour method are adopted to characterize the overall distribution of the residual stress. As shown in Figure 12, the FEM results in the quenching and cold pressing agree with the experiments, indicating the validity of the FEM models. It can be seen that most of the simulated residual stress is within the error bar of the experimental results. The error is defined in Equation (3). The maximum error is located at the bottom surface of the quenched sample as shown in Figure 12b. The maximum error is $9.5 \%$, thus indicating that the FEM models can predict the residual stress distribution of the T-type rib.

$$
e=\left|\sigma_{\mathrm{e}}-\sigma_{\mathrm{F}}\right| / \sigma_{\mathrm{e}} \times 100 \%
$$

where $e$ is error, $\sigma_{\mathrm{e}}$ and $\sigma_{\mathrm{F}}$ are experimental values and simulated values of residual stress.

\subsection{Stress Reduction Mechanism}

The inhomogeneous deformation induced from the temperature gradient during the cooling process is the main reason for the formation of quenched residual stress. It is related to the geometry, elasticity modulus, heat conductivity coefficient, expansion coefficient and microstructure of the component. Compressive residual stress may be generated on 
the area with low yield strength and large plastic strain after unloading the force. The heat exchange of the T-type rib is quite different to that of the plate during the quenching process, thus resulting in different residual stress distribution.
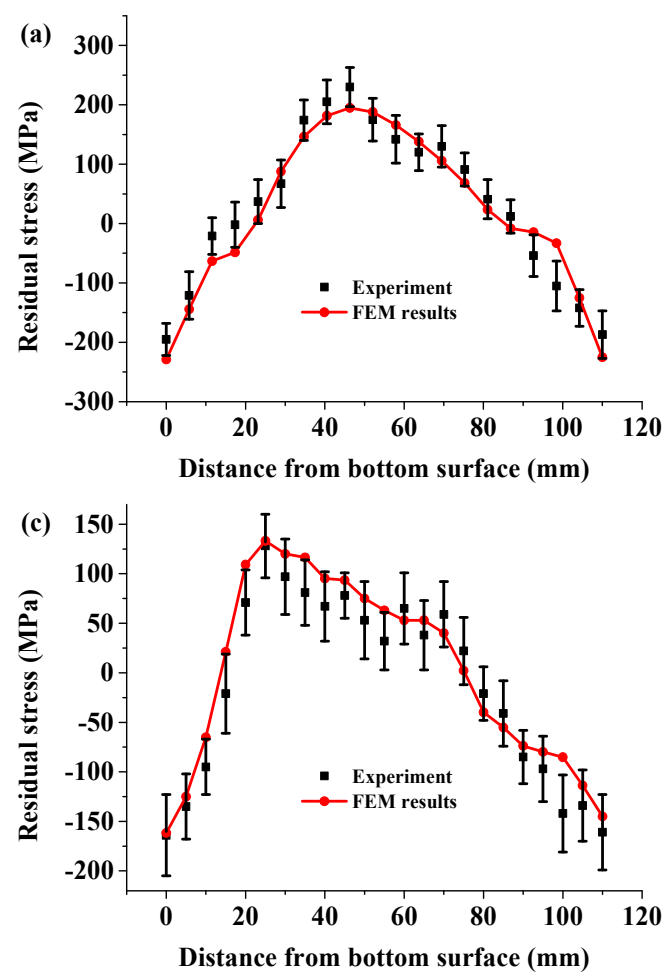
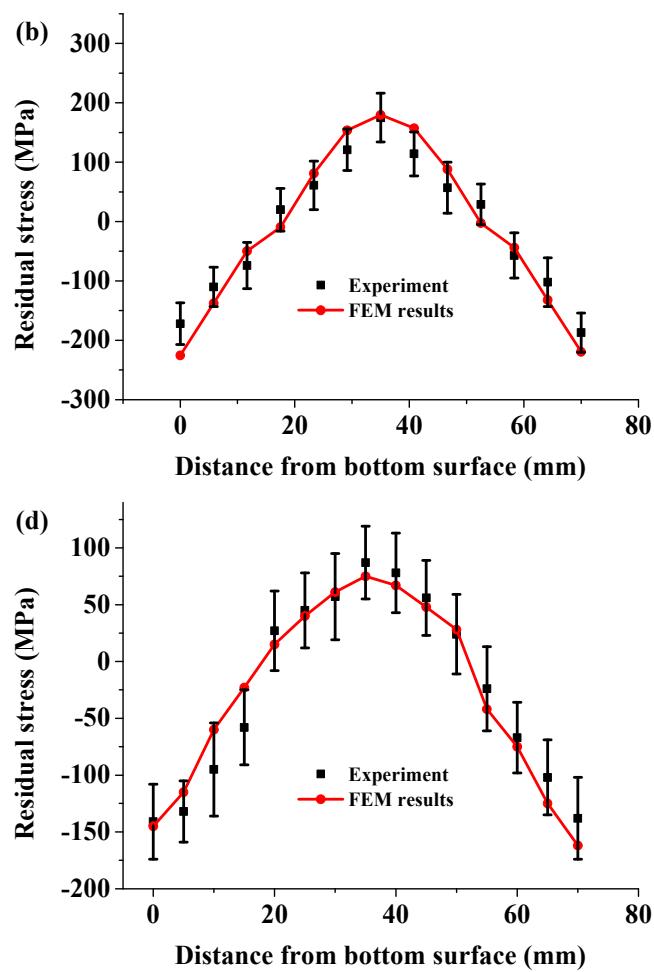

Figure 12. Comparisons between FEM and experimental results: $(\mathbf{a}, \mathbf{b})$ for quenched stress along path ab and cd, respectively; (c,d) for cold pressed stress along path ab and cd, respectively.

When the quenched T-type rib is subjected to cold pressing, plastic strain first initiates on the surfaces of the component due to its large residual stress after the quenching stage. Then, the strain is penetrated into the center zone of the component. As shown in Figure 7, the inhomogeneous strain between the surface and the center zone of the component is induced during the cold pressing. This will generate a new distribution of the residual stress, which is tensile stress on the surface and compressive stress on the center zone. It is interesting that the induced residual stress distribution in the cold pressing is contrary to that in the quenching stage. The superposition of the residual stress in the quenched and cold pressed stage will decrease the value of the residual stress, thus achieving the reduction of residual stress.

As shown in Figure 8, the distribution of the residual stress in the integral cold pressing is more uniform than that in the stepwise cold pressing, especially for the smooth area of the T-type rib. The stress reduction at the stiffened area is similar for the integral and stepwise cold pressing as the strain variation at the stiffened area is quite heterogeneous, as shown in Figure 7. Nevertheless, there is an overlap zone at the smooth area with the adjacent pass of the stepwise cold pressing. The strain at the overlap zone is quite different from that at the non-overlap zone, thus resulting in the inhomogeneous distribution of the residual stress and heterogeneous stress reduction. Therefore, less passes of the cold pressing should be adopted to decrease the inhomogeneity of the residual stress within the capacity of the cold pressing machine.

The stress reduction mechanism of the artificial aging mainly consists of stress relaxation and the effect of second phases. The yield strength of the material decreases with the increased temperature, and plastic strain is generated when the residual stress exceeds the decreased yield strength. This is the mechanism of stress relaxation, and it contributes to the stress reduction during the aging process. In addition, precipitation 
decomposition of the supersaturated solid solution will be generated in the initial stage of the aging treatment. The second phases of the GP zone and the strengthening phase $\eta^{\prime}\left(\mathrm{MgZn}_{2}\right)$ may be precipitated. The compressive residual stress induced from the previous process decreases the lattice constant of the matrix and the tensile residual stress will be generated around the $\eta^{\prime}$ phase. There is a superimposed effect between the high elastic stress field around the second phases and the residual stress generated in the previous processes of the component, thus decreasing the residual stress during the aging process.

\section{Conclusions}

(1) Both the quenched and cold pressed residual stress show a lamination distributional type with compressive stress at its surfaces and tensile stress at the center layers. The distribution of residual stress at the stiffened area is asymmetrical, and it is symmetrical at the smooth area.

(2) The integral and five-pass stepwise cold pressing results in heterogeneous distribution of residual stress and strain at the stiffened area. Meanwhile, the stepwise cold pressing also induces inhomogeneous distribution of residual stress and strain at the overlap regions.

(3) There is no difference between the longitudinal and transverse stress at the smooth area for the quenched and cold pressed components; meanwhile, there is a significant distinction at the stiffened area.

(4) The whole distribution of residual stress for the T-type rib is measured using X-ray diffraction and the contour method and they agree with the simulated results. The cold pressing followed by the aging process contribute to a stress reduction of $50 \%$ on the surfaces of the T-type rib.

(5) The smooth area shows a more significant reduction of maximum tensile residual stress in comparison with that of the stiffened area. The reduction of the maximum tensile stress at the stiffened area is $42 \%$ and $50 \%$ for the cold pressing and aging, which increases to $54 \%$ and $60 \%$ at the smooth area, respectively.

(6) The mechanism of the stress reduction during the cold pressing and the aging processes is discussed.

Author Contributions: Conceptualization, writing, Y.L.; supervision, writing, T.Z.; methodology, Y.W.; review and editing, H.G. All authors have read and agreed to the published version of the manuscript.

Funding: This project is supported by National Natural Science Foundation of China (Grant No.51705248, No. 51327902); State Key Laboratory for High Performance Complex Manufacturing, Central South University (ZZYJKT2021-05).

Institutional Review Board Statement: Not applicable.

Informed Consent Statement: Not applicable.

Data Availability Statement: Data are contained within the article.

Conflicts of Interest: The authors declare no conflict of interest.

\section{References}

1. Liu, H.; Zheng, J.; Guo, Y.; Zhu, L. Residual Stresses in High-speed Two-dimensional Ultrasonic Rolling 7050 Aluminum Alloy with Thermal-Mechanical Coupling. Int. J. Mech. Sci. 2020, 186, 105824. [CrossRef]

2. Meng, Y.; Wang, X.; Hao, Z.; Fu, X. The Influence of Forming Directions and Strain Rate on Dynamic Shear Properties of Aerial Aluminum Alloy. Appl. Sci. 2018, 8, 520. [CrossRef]

3. Yu, X.W.; Chen, J.H.; Li, J.Y.; Wu, C.L.; Yang, X.B. Effect of pre-deformation on quench-induced inhomogeneity of microstructure and hardness in 7050 aluminum alloy. Mater. Charact. 2019, 158, 110005. [CrossRef]

4. Chen, Y.; Liu, Z.; Bai, S.; Zhao, J.; Liu, G. The Effect of Multistage Aging on Mechanical Properties and Microstructure of Forged 7050 Aluminum Alloys. J. Mater. Eng. Perform. 2019, 28, 3590-3599. [CrossRef]

5. Dong, F.; Yi, Y.; Huang, S.; He, H.; Huang, K. Refinement of second-phase particles and grain structures of $2219 \mathrm{Al}$ cu alloy forgings using an improved thermomechanical treatment process. Mater. Charact. 2021, 173, 110927. [CrossRef] 
6. Xu, L.; Zhan, L.; Xu, Y.; Liu, C.; Huang, M. Thermomechanical Pretreatment of Al-Zn-Mg-Cu Alloy to Improve Formability and Performance during Creep-age Forming. J. Mater. Process. Technol. 2021, 293, 117089. [CrossRef]

7. He, H.; Yi, Y.; Huang, S.; Guo, W.; Zhang, Y. Effects of thermomechanical treatment on grain refinement, second-phase particle dissolution, and mechanical properties of $2219 \mathrm{Al}$ alloy. J. Mater. Process. Technol. 2019, 278, 116506. [CrossRef]

8. Chen, Z.; Yuan, Z.; Ren, J. The mechanism of comprehensive properties enhancement in Al-Zn-Mg-Cu alloy via novel thermomechanical treatment. J. Alloys Compd. 2020, 828, 154446. [CrossRef]

9. Chobaut, N.; Carron, D.; Arsène, S.; Schloth, P.; Drezet, J.M. Quench induced residual stress prediction in heat treatable 7xxx aluminium alloy thick plates using Gleeble interrupted quench tests. J. Mater. Process. Technol. 2015, 222, 373-380. [CrossRef]

10. Bouissa, Y.; Bohlooli, N.; Shahriari, D.; Champliaud, H.; Jahazi, M. FEM modeling and experimental validation of quench-induced distortions of large size steel forgings. J. Manuf. Process. 2020, 58, 592-605. [CrossRef]

11. Zhang, Y.; Yi, Y.; Huang, S.; He, H. Influence of Temperature-Dependent Properties of Aluminum Alloy on Evolution of Plastic Strain and Residual Stress during Quenching Process. Metals 2017, 7, 228. [CrossRef]

12. Cong, W.; Luo, T.; Zhou, J.; Yang, Y. Effects of solution and quenching treatment on the residual stress in extruded ZK60 magnesium alloy. Mater. Sci. Eng. A 2018, 722, 14-19.

13. Masoudi, S.; Amirian, G.; Saeedi, E.; Ahmadi, M. The Effect of Quench-Induced Residual Stresses on the Distortion of Machined Thin-Walled Parts. J. Mater. Eng. Perform. 2015, 24, 3933-3941. [CrossRef]

14. Robinson, J.S.; Tiernan, P.J.; Kelleher, J.F. Effect of post-quench delay on stress relieving by cold compression for the aluminium alloy 7050. Mater. Sci. Technol. 2015, 31, 409-417. [CrossRef]

15. Zhang, Y.X.; Yi, Y.P.; Huang, S.Q.; Dong, F. Influence of quenching cooling rate on residual stress and tensile properties of 2A14 aluminum alloy forgings. Mater. Sci. Eng. A 2016, 674, 658-665. [CrossRef]

16. Guo, R.; Wu, J. Dislocation density based model for Al-Cu-Mg alloy during quenching with considering the quench-induced precipitates. J. Alloys Compd. 2018, 741, 432-441. [CrossRef]

17. Tanner, D.A.; Robinson, J.S. Modelling stress reduction techniques of cold compression and stretching in wrought aluminium alloy products. Finite Elem. Anal. Des. 2003, 39, 369-386. [CrossRef]

18. Zheng, Z.; Yang, Y.; Liang, L.; Bo, C.; Hui, T. Assessment of residual stress of 7050-T7452 aluminum alloy forging using the contour method. Mater. Sci. Eng. A 2015, 644, 61-68. [CrossRef]

19. Cui, J.D.; Yi, Y.P.; Luo, G.Y. Numerical and Experimental Research on Cold Compression Deformation Method for Reducing Quenching Residual Stress of 7A85 Aluminum Alloy Thick Block Forging. Adv. Mater. Sci. Eng. 2017, 2017, 1-6. [CrossRef]

20. Liu, X.; Robert, C.; Gong, H.; Liu, Y.; Chen, D.; Liu, Y.; Wu, Y.; Li, C. Residual Stress Determination in Quenched and Cold Compressed T-section 7050 Forging by Neutron Diffraction and Contour Method. Annu. Rep. China Inst. At. Energy 2018, 27, 6049-6057. [CrossRef]

21. Ko, M.; Culp, J.; Altan, T. Prediction of residual stresses in quenched aluminum blocks and their reduction through cold working processes. J. Mater. Process. Technol. 2006, 174, 342-354.

22. Dai, W.; Yi, Y.; Cui, J. Reduction of quenching residual stress for 7A85 aluminum alloy forging by cold compression. J. Cent. South Univ. 2015, 46, 1609-1614.

23. Pan, R.; Shi, Z.; Davies, C.M.; Li, C.; Kaye, M.; Lin, J. An integrated model to predict residual stress reduction by multiple cold forging operations in extra-large AA7050 T-section panels. Proc. Inst. Mech. Eng. B-J. Eng. 2018, 232, 1319-1330. [CrossRef]

24. Godlewski, L.A.; Su, X.; Pollock, T.M.; Allison, J.E. The Effect of Aging on the Relaxation of Residual Stress in Cast Aluminum. Metall. Mater. Trans. A 2013, 44, 4809-4818. [CrossRef]

25. Bai, Q.; Feng, H.; Si, L.K.; Pan, R.; Wang, Y.Q. A Novel Stress Relaxation Modeling for Predicting the Change of Residual Stress During Annealing Heat Treatment. Metall. Mater. Trans. A 2019, 50, 5750-5759. [CrossRef]

26. Rahimi, S.; King, M.; Dumont, C. Stress relaxation behaviour in IN718 nickel based superalloy during ageing heat treatments. Mater. Sci. Eng. A 2017, 708, 563-573. [CrossRef]

27. Zhang, Z.; Feng, Y.; Tan, Q.; Zou, J.; Li, J.; Zhou, X. Residual stress distribution in Ni-based superalloy turbine discs during fabrication evaluated by neutron/X-ray diffraction measurement and thermomechanical simulation. Mater. Des. 2019, 166, 107603. [CrossRef]

28. Dong, Y.; Shao, W.; Lu, L.; Jiang, J.; Zhen, L. Numerical Simulation of Residual Stress in an Al-Cu Alloy Block During Quenching and Aging. J. Mater. Eng. Perform. 2015, 24, 4928-4940. [CrossRef]

29. Aba-Perea, P.E.; Withers, P.J.; Pirling, T.; Paradowska, A.; Preuss, M. In Situ Study of the Stress Relaxation During Aging of Nickel-Base Superalloy Forgings. Metall. Mater. Trans. A 2019, 50, 3555-3565. [CrossRef]

30. Sun, Y.; Jiang, F.; Hui, Z.; Jian, S.; Yuan, W. Residual stress relief in Al-Zn-Mg-Cu alloy by a new multistage interrupted artificial aging treatment. Mater. Des. 2016, 92, 281-287. [CrossRef]

31. Wang, J.; Hsieh, C.; Lai, H.; Kuo, C.; Wu, P.; Wu, W. The relationships between residual stress relaxation and texture development in AZ31 Mg alloys via the vibratory stress relief technique. Mater. Charact. 2015, 99, 248-253. [CrossRef] 